\title{
Herbivores avoid host plants previously exposed to their omnivorous predator Macrolophus pygmaeus
}

\author{
Nina Xiaoning Zhang ${ }^{1} \cdot$ Daan van Wieringen ${ }^{1} \cdot$ Gerben J. Messelink ${ }^{2} \cdot$ Arne Janssen $^{1}$ (i)
}

Received: 19 April 2018 / Revised: 5 August 2018 / Accepted: 6 August 2018 / Published online: 11 August 2018

(c) The Author(s) 2018

\begin{abstract}
Herbivorous arthropods use various cues to choose suitable host plants. We investigated whether three species of herbivores use cues associated with their omnivorous predator Macrolophus pygmaeus to select host plants. Earlier, we found that this omnivore induces plant defences which decreased the performance of two of the herbivores, i.e. the spider mite Tetranychus urticae and the western flower thrips Frankliniella occidentalis, whereas the green peach aphid Myzus persicae was not affected. Hence, the spider mite and thrips were expected to avoid plants that were previously exposed to M. pygmaeus because of their lower quality, and the aphid was not expected to avoid exposed plants because they were of equal quality as unexposed plants. However, the cues left behind by M. pygmaeus may also be indicative of predation risk, in which case all three herbivores were expected to avoid exposed plants. Spider mites and western flower thrips preferred clean plants over plants that had previously been exposed to M. pygmaeus, but no longer harboured this omnivore. Aphids showed no preference, in agreement with their performance, but not in agreement with reducing predation risk. We furthermore showed that the preference of spider mites and thrips for clean plants increased through time. Higher proportions of aphids left plants previously exposed to $M$. pygmaeus than clean plants through time. Hence, omnivorous predators can decrease herbivore densities on plants not only by killing them but also by indirectly affecting herbivore host plant selection.
\end{abstract}

Keywords Omnivore · Macrolophus pygmaeus $\cdot$ Herbivore host plant selection · Predation risk · Induced defence · Herbivore performance

\section{Key message}

- Omnivorous predators may affect host plant choice of herbivores by decreasing plant quality through induction of defences and cues indicating predation risk.

- Spider mites and thrips preferred clean plant over plants previously exposed to their omnivorous predator. Aphids showed no preference, but a higher proportion left the exposed plants.

Communicated by M. Traugott.

Arne Janssen

arne.janssen@uva.nl

1 IBED, Evolutionary and Population Biology, University of Amsterdam, Science Park 904, 1098 XH Amsterdam, The Netherlands

2 Wageningen UR Greenhouse Horticulture, PO Box 20, 2265 ZG Bleiswijk, The Netherlands
- Omnivorous predators can decrease herbivore densities on plants not only by killing them but also by indirectly affecting herbivore host plant selection, resulting in lower pest densities on the plant.

\section{Introduction}

To find a suitable host plant for feeding and oviposition, herbivores use cues associated with the host plant quality (Dicke 2000), the likelihood of food competition (Bernays and Chapman 1994; Pallini et al. 1997) and the risk of predation (Lima and Dill 1990; Janssen et al. 1998; Grostal and Dicke 1999). From a distance, olfactory and visual cues are important for host plant selection by herbivores (Bernays and Chapman 1994). For example, whiteflies use colours, and aphids use both visual and olfactory cues to direct their flight to host plants (Gerling 1990; Powell et al. 2006).

Volatile cues used by herbivores can be those produced constitutively by their host plants (Visser 1986; Pallini et al. 
1997, 1999a, b), which can provide specific information about the quality of the plants. Volatiles associated with the presence of competitors and predators are also known to play a role in herbivore host plant selection (Pallini et al. 1997, 1999a, b; Nomikou et al. 2003; Meng et al. 2006; Dias et al. 2016; Darshanee et al. 2017). Upon attack by herbivores, plants produce volatiles that are often used by the natural enemies of the herbivores to locate their prey (Dicke and Sabelis 1988; Turlings et al. 1990; Takabayashi et al. 2006), and this information is also picked up by other herbivores that can use it to locate suitable host plants (Shiojiri et al. 2002; Sabelis et al. 2007). Some herbivores are repelled by volatiles from plants with conspecifics or heterospecifics to avoid competition and predation risk (Pallini et al. 1997; De Moraes et al. 2001; Agut et al. 2005), but there are also examples of herbivores that are attracted by the volatiles from plants with conspecifics (Harari et al. 1994; Loughrin et al. 1995; Bolter et al. 1997; Agut et al. 2005; Sarmento et al. 2011).

After contact with a plant, herbivores are exposed to other cues. Both physical and chemical cues on the plant surface can arrest or repel herbivores (Müller and Riederer 2005). For example, whiteflies prefer plants with non-glandular trichomes over glabrous plants (Neal and Bentz 1999), whereas other herbivores find refuge from predators under glandular trichomes (van Houten et al. 2013). Herbivores can also use tactile and gustatory cues to assess plant quality (Gerling 1990; Powell et al. 2006; Walling 2008). Phloem feeders such as whiteflies and aphids can taste the chemical defences in the phylloplane and detect the presence or absence of secondary metabolites to determine whether the plant is a suitable host (Müller and Riederer 2005; Walling 2008). Herbivore feeding induces so-called direct plant defences that result in the production of specific compounds that can decrease the development and survival of herbivores (Karban and Baldwin 1997), and these compounds can affect the choice of other herbivores when arriving on the plant. Some herbivores may be deterred after detecting induced defences, but herbivores that can tolerate and suppress induced defences may stay on the host plant (Zarate et al. 2007; Walling 2008). Thus, feeding by one species can affect the host plant choice of other species (Karban and Baldwin 1997).

Other cues left by competitors and predators may also affect host plant selection (Bernays and Chapman 1994), for example chemical markings left behind by competitors deter butterflies (Schoonhoven 1990), and several herbivore species avoid plants with cues of predators (Meng et al. 2006; Choh and Takabayashi 2007; Lee et al. 2011). In contrast, some herbivores that benefit from the presence of predators of other herbivore species will prefer plants with cues from these carnivores (Atsatt 1981; Pierce and Elgar 1985; Wagner and Kurina 1997). For example, aphids and lycaenid caterpillars prefer plants with ants over ant-free plants, because ants can help them defend against their enemies (Pierce and Young 1986; Müller and Godfray 1999).

Omnivorous predators prey on herbivores but also feed on plants. Therefore, omnivorous predators can affect herbivore populations directly by preying on them as well as indirectly through plant-mediated effects and through cues left by the omnivores. It is known that several omnivores induce direct plant defences when feeding on a plant (Pappas et al. 2015; Pérez-Hedo et al. 2015a, b; Bouagga et al. 2018; Zhang et al. 2018). Earlier, we showed that feeding of Macrolophus pygmaeus on sweet pepper plants induced direct plant defences, resulting in reduced performance of two-spotted spider mites (Tetranychus urticae) and western flower thrips (Frankliniella occidentalis) on these plants, but the performance of green peach aphids (Myzus persicae) was unaffected by previous omnivore plant feeding (Zhang et al. 2018). Omnivore feeding also resulted in increased concentrations of defence related plant pheromones in sweet pepper plants, indicating that direct defences were induced (Zhang et al. 2018). During these experiments, we observed that herbivores tried to escape from plants previously exposed to M. pygmaeus, indicating that herbivores might avoid these plants. We therefore tested the effects of previous exposure of plants to omnivores on the host plant choice of these herbivores.

Omnivorous predators can affect the host plant choice of herbivores in different ways. First, plant feeding by omnivorous predators can induce direct plant defences, decreasing the quality of the host plants and consequently the preference of the herbivores. Second, herbivores may avoid plants with cues of omnivores to avoid plants on which they would experience a high predation risk. We investigated the effects of previous exposure of plants to M. pygmaeus on the host plant choice of two-spotted spider mites, western flower thrips and green peach aphids. The herbivores were allowed to perceive plant cues from a distance, but could also enter the plants and use short-range cues in deciding to stay or to leave. Based on their performance on M. pygmaeus-exposed plants, we expected that the first two herbivore species would avoid settling on these plants, whereas the aphids would not. Based on the perception of cues associated with predation risk, we expected that all three herbivore species would avoid plants previously exposed to the omnivore.

\section{Materials and methods}

\section{Plant material}

Sweet pepper plants (Capsicum annuum L. cv. Spider F1 Enza Zaden, the Netherlands) were grown from seeds in soil pots $(\varnothing=14 \mathrm{~cm})$ filled with a standard fertilized peat mixture for young plants $(50 \%$ coco peat, $15 \%$ white peat, 
$35 \%$ frozen black peat, Jongkind Grond BV, Aalsmeer) in a climate room dedicated to grow clean plants $\left(25 \pm 1{ }^{\circ} \mathrm{C}\right.$, 60-70\% RH, 16: 8 L: D). Water was supplied twice a week, and plants did not receive fertilizers or pesticides. Fourweek-old plants with 6-8 true leaves (about $20 \mathrm{~cm}$ high) were used for experiments. Plants of 5-8 weeks old were used for the rearing of spider mites, thrips and aphids.

\section{Cultures}

A culture of M. pygmaeus was established with fifth-instar nymphs from a commercial company (Koppert Biological Systems BV, Berkel en Rodenrijs, the Netherlands). It was reared in plastic containers (height $=45 \mathrm{~cm}, \varnothing=35 \mathrm{~cm}$ ) in a climate room (conditions as above) with Ephestia kuehniella eggs as food and green bean pods as both food supply and oviposition substrate. New E. kuehniella eggs and beans were added twice a week. Old beans with $M$. pygmaeus eggs were transferred to new containers and kept until the eggs hatched, whereupon E. kuehniella eggs and beans were supplied twice a week. Old beans from which nymphs no longer hatched were removed from the containers. Adults of 4-8 days-old were used for experiments.

The culture of $T$. urticae was started with individuals obtained from a cucumber colony in our laboratory (see Janssen 1999 for details) and was reared on intact sweet pepper plants in a climate room (conditions as above). New plants were provided twice a week. The colony was cultivated for 18 months on sweet pepper plants before being used for experiments. Thus, T. urticae females used in the experiments below were adapted to sweet pepper plants.

A red phenotype of $M$. persicae was obtained from a culture on sweet pepper plants (cv Ferrari, Enza Zaden, the Netherlands) at Wageningen UR Greenhouse Horticulture (Bleiswijk, the Netherlands). The culture was established by placing all individuals on intact sweet pepper plants in insect-proof cages (BugDorm-44545F, $47.5 \times 47.5 \times 47.5 \mathrm{~cm}$, mesh size $160 \mu \mathrm{m})$ in a climate chamber (conditions as above). New plants were supplied every two weeks. We used apterous females for the experiments.

A culture of $F$. occidentalis that originated from the stock colony of Koppert Biological Systems was maintained on bean pods and cattail pollen Typha latifolia $\mathrm{L}$. These thrips were subsequently reared on sweet pepper plants supplemented with cattail pollen in fine-mesh cages (as above) in a climate chamber (conditions as above). New pollen was applied on sweet pepper leaves with a fine brush three times per week, and new plants were supplied twice per week. In order to obtain cohorts of thrips larvae, adult thrips were collected with an aspirator connected to a vacuum pump and placed on clean sweet pepper leaves on soaked cotton wool in Petri dishes sealed with Parafilm. The lids had ventilation holes covered with a fine mesh for ventilation. Adults were removed after $24 \mathrm{~h}$, and leaves were kept until new larvae hatched. Thereafter, new leaves and pollen were added. In this way, cohorts of similar-aged adults were obtained for experiments.

\section{Exposure of sweet pepper plants with M. pygmaeus}

Exposure of sweet pepper plants to M. pygmaeus was done as described previously (Zhang et al. 2018). In short, fourweek-old plants with 6-8 true leaves were each transferred into a separate insect-proof cage (same type as above) in a climate chamber (conditions as above). Five adult females and five adult males of M. pygmaeus were released in half of the cages, haphazardly chosen, and plants in these cages served as treated plants. The other plants were clean and served as control plants. After 4 days, all M. pygmaeus were removed from the treated plants. No food or prey was supplied for M. pygmaeus during these 4 days, thus preventing females from ovipositing (Perdikis and Lykouressis 2004). An average of $60 \%$ of the females of M. pygmaeus was alive after these 4 days, ensuring that the plants were exposed to feeding omnivores during the entire period.

\section{Host plant choice by two-spotted spider mites}

One plant treated with M. pygmaeus as above and one clean plant were transferred into an insect-proof cage (BugDorm$44590 \mathrm{DHF}, 93.0 \times 47.5 \times 47.5 \mathrm{~cm}$, mesh size $160 \mu \mathrm{m})$ in a climate chamber (same condition as above). The plants were placed in a plastic tray $(49 \times 31 \mathrm{~cm})$ filled with water, on opposite sides and $30 \mathrm{~cm}$ away from the centre of the tray. A pot $(\varnothing=8 \mathrm{~cm})$ was placed bottom up in the centre of each tray, on top of which a plastic cup was placed. A string (Nylon, Hema, the Netherlands) was tied around the base of the 4th leaf of each plant, and the other end was fixed to the rim of the cup with a paperclip with the end of the string reaching the bottom of the cup. These strings served as bridges between the cup and the plants. One hundred adult female spider mites were collected from the culture, were starved for $1 \mathrm{~h}$ in four 1.5-mL Eppendorf safe-lock tubes and were subsequently released in the centre of the cup. Spider mites on the plants were counted four times after the release, with 1-h intervals between the end of one counting and the start of the next one, and again after $24 \mathrm{~h}$. Fourteen pairs of plants were used in total, divided over three blocks in time, each pair in a separate cage. To remove possible effects of directionality in the mite movement (Janssen 1999), the position of treated and control plants was alternated among cages. The numbers of spider mites found on the two plants per sampling time were compared using a linear mixedeffects model (LME), with treatment, time and their interaction as fixed factors, and individual plant as random factor. The distribution of the residuals was checked for normality. 
Non-significant interactions and factors were removed until a minimal adequate model was reached (Crawley 2013). Contrasts for each sampling period were assessed with the Tukey method (package lsmeans in R, Lenth 2016). All statistical analyses were performed with R (R Core Development Team 2014).

\section{Host plant choice by green peach aphids}

A similar set-up as above was used for host plant choice experiments with aphids with some minor modifications. One string was used to make a horizontal connection between the clean and treated plant, with each end tied around the stem (between the 5th and 6th leaf) of one of the two plants. Another string was tied to the centre of this horizontal string, and the other end was fixed onto the cup (as described above) where aphids were released. Twenty female aphids from the colony, starved for $2 \mathrm{~h}$ in an Eppendorf tube (as above), were released in the cup. Thereafter, the numbers of aphids that arrived on the plants and the time when an aphid arrived on and left from a plant were recorded. Observations were done at shorter intervals than for spider mites because the aphids made choices much faster than spider mites. Almost all aphids made a choice within 45 min after being released. Aphids on each plant were counted again $24 \mathrm{~h}$ after the release. Experiments were conducted in two blocks in time with five pairs of plants per block. Again, the position of treated and control plants was alternated among cages. The cumulative number of aphids that arrived on each plant was calculated every $5 \mathrm{~min}$ for the first $45 \mathrm{~min}$. These data were compared using an LME as described above, with treatment and time and their interaction as fixed factors, and individual plant as random factor. The distribution of the residuals was checked for normality. The proportions of aphids that had left each plant after $45 \mathrm{~min}$ and $24 \mathrm{~h}$ were compared between plant treatments with a generalized linear model (GLM).

\section{Host plant choice by western flower thrips}

Because adult thrips fly when searching for host plants, we used a different set-up to test their host plant choice, based on earlier experiments (Pallini et al. 1999a, b). Plants, treated as above, were transferred to a greenhouse compartment $\left(25 \pm 1{ }^{\circ} \mathrm{C}, 60-70 \% \mathrm{RH}, 16: 8 \mathrm{~L}\right.$ : D) at the University of Amsterdam the day before the experiments and placed inside an insect-proof cage $(203 \times 86.5 \times 84 \mathrm{~cm})$. Two treated and two clean plants were placed in a square with equal distances $(35.5 \mathrm{~cm})$ to the centre, and the positions of treated and clean plants were alternated. A small pot $(9 \times 9 \times 9.7 \mathrm{~cm})$ was placed upside down in the centre of the square serving as the release point. The 3rd leaf of each plant pointed towards the release point. A group of 100 female thrips were collected from the culture and starved for $90 \mathrm{~min}$ in four $1000-\mu \mathrm{L}$ Eppendorf pipette tips, closed with Parafilm, with 25 thrips in each tip. Tips with starved thrips were placed at the four corners of the pot at the release site, and the thrips were released by removing the Parafilm. The number of thrips on each plant was assessed six times with 1-h intervals by removing the thrips from the plants with an aspirator while counting them. Thereafter, numbers of thrips on each plant and those inside the tubes at the release point were assessed $24 \mathrm{~h}$ after release. To avoid effects of directionality, the position of the treated and untreated plants was alternated among replicates. There were nine replicates, each with two control and two treated plants, with one or two replicates on a single day. The cumulative numbers of adult thrips encountered on the plants at each count were $\log (x+10)$-transformed and compared using an LME following the same procedure as above, with treatment and time and their interaction as fixed factors, and individual plant as random factor. The distribution of the residuals was checked for normality. Contrasts were assessed with the Tukey method (package lsmeans in R, Lenth 2016).

Because the thrips were removed from the plants while counting, thrips had limited time to choose a host plant, and even less time to assess the quality of the plant by probing (Harrewijn et al. 1996). Therefore, a second group of experiments was done as above, but thrips were removed only after $24 \mathrm{~h}$, not after each sampling. This experiment was replicated six times, and the numbers of thrips $(\log (x+1)$-transformed) were compared as above. To compare the two experiments, the cumulative numbers of thrips on the plants after $24 \mathrm{~h}$ were compared with a GLM with a quasi-Poisson error distribution using experiment as factor.

Four of these six replicates in this latter experiment were used to assess the oviposition of the thrips on the plants. To this end, plants were transferred individually into cages (BugDorm-44590DHF, $93.0 \times 47.5 \times 47.5 \mathrm{~cm}$, mesh size $160 \mu \mathrm{m}$ ) after each replicate, and the numbers of larvae hatching from the eggs on each plant were counted 4 days later as an indication of the oviposition rate. To check for differences in oviposition plus egg survival on the plants, the numbers of larvae were compared with a generalized mixed-effects model (GLMER from the package lme4, Bates et al. 2015) with a Poisson error distribution with treatment and the numbers of female thrips encountered on the plants and their interaction as fixed factors and replicate as random factor.

\section{Results}

\section{Host plant choice by two-spotted spider mites}

The numbers of spider mites on clean plants increased over time, and the numbers of spider mites on the M. pygmaeustreated plants increased during the first $3 \mathrm{~h}$ but subsequently 
decreased from the 3rd to the 4th hour (Fig. 1), resulting in a significant effect of the interaction between treatment and time (LME: $\chi^{2}=23.95, d f=4, P<0.0001$ ). Significantly lower numbers of spider mites were found on the treated plants than on clean plants after $4 \mathrm{~h}$ and $24 \mathrm{~h}$ (Fig. 1, contrasts with glht function of package lsmeans).

\section{Host plant choice by green peach aphids}

The numbers of aphids on M. pygmaeus-treated plants and control plants did not differ significantly (Fig. 2a, LME: $\chi^{2}=2.91, d f=1, P=0.088$ ), and there was no significant interaction of treatment with time $\left(\chi^{2}=14.0, d f=8\right.$; $P=0.083$ ). The numbers of aphids on the plants increased significantly with time (Fig. 2a, LME: $\chi^{2}=239.5, d f=8$, $P<0.0001)$. Significantly higher proportions of aphids left the treated plants than the control plants after $45 \mathrm{~min}$ and 24 h (Fig. 2b, GLM, 45 min: $\chi^{2}=6.74, d f=1, P=0.0094$; $\left.24 \mathrm{~h}: \chi^{2}=14.2, d f=1, P=0.00017\right)$.

\section{Host plant choice by western flower thrips}

When thrips were recaptured within $1 \mathrm{~h}$ of arriving on the plants, the cumulative numbers of thrips found on clean plants increased faster through time than those on $M$. pygmaeus-exposed plants (Fig. 3a), resulting in a significant effect of the interaction between treatment and time (LME: $\left.\chi^{2}=14.1, d f=4, P=0.0285\right)$. Significantly higher numbers of thrips were found on the clean plants after 5, 6 and $24 \mathrm{~h}$ (Fig. 3a, contrasts after LME). When thrips were not removed from the plants during each sampling, significantly

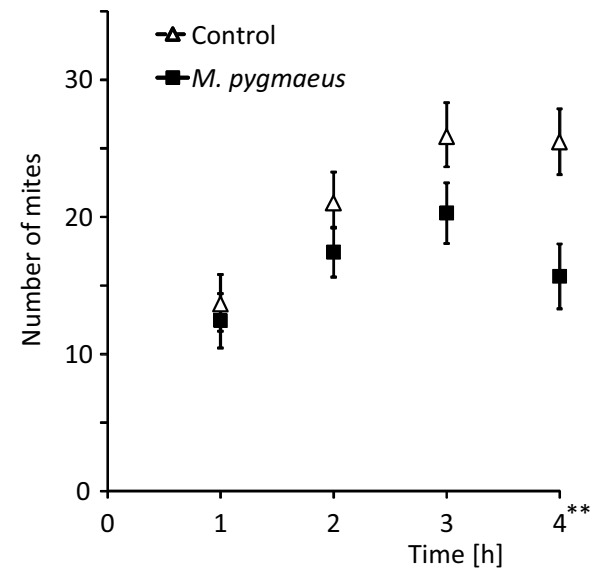

I

Fig. 1 Effect of previous exposure of plants to M. pygmaeus on the host plant choice of spider mites T. urticae. Shown are average cumulative numbers $( \pm \mathrm{SE})$ of spider mites on plants previously exposed to $M$. pygmaeus for 4 days (closed squares) and clean plants (control, open triangles) over time. Significant differences between $M$. pygmaeus-treated and clean plants at each time point are indicated by asterisks (contrasts after LME, $* * P<0.01$ )

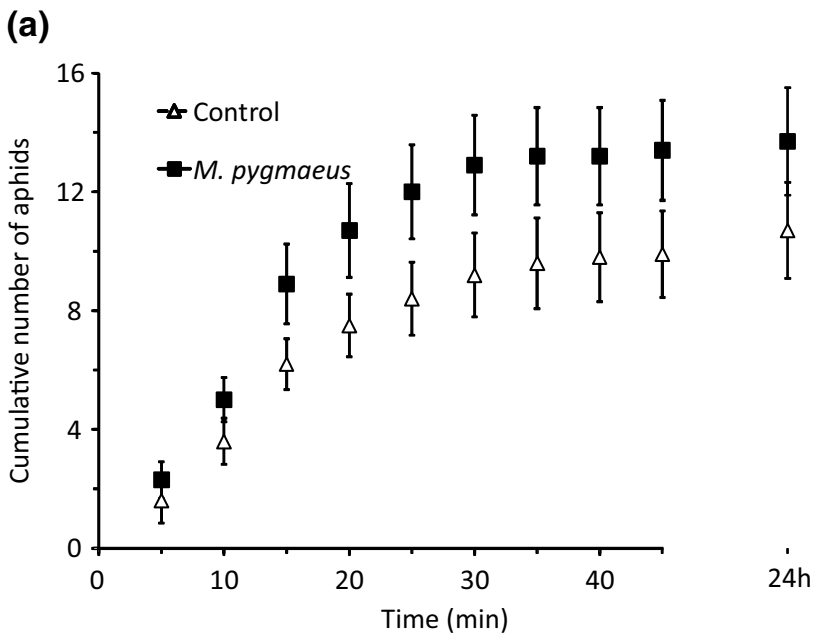

(b)

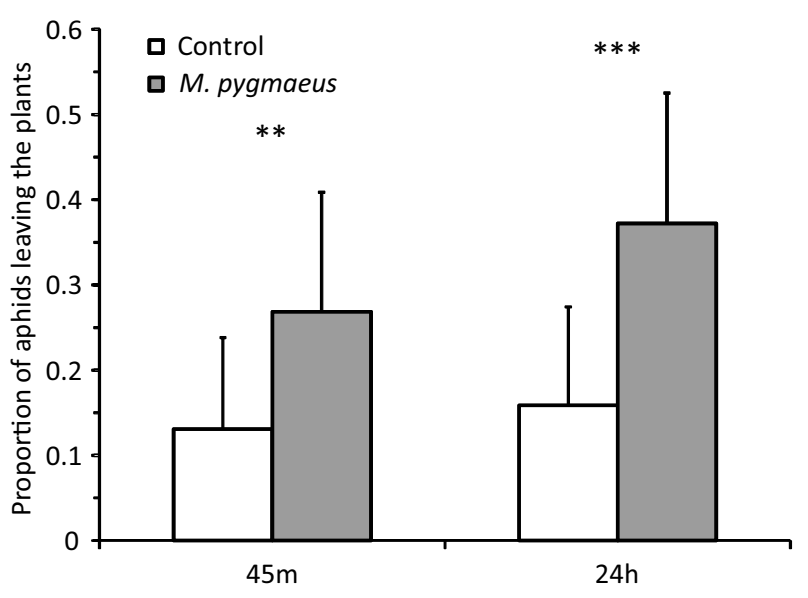

Fig. 2 Effect of previous exposure of plants to M. pygmaeus on the host plant choice of apterous aphids $M$. persicae. a Average cumulative numbers of aphids $( \pm$ SE) arriving on plants previously exposed to M. pygmaeus for 4 days (closed squares) and clean plants (control, open triangles) over time (during $45 \mathrm{~min}$ and after $24 \mathrm{~h}$ ). b Proportions of aphids $( \pm \mathrm{SE})$ that left plants previously exposed to $M$. pygmaeus (grey bars) and clean plants (control, white bars) after 45 min and $24 \mathrm{~h}$. Significant differences between M. pygmaeus-treated and clean plants are indicated by asterisks (contrasts after GLM, $* * P<0.01, * * * P<0.001)$

higher numbers were found on the clean plants than on the M. pygmaeus-exposed plants throughout the experiment (Fig. 3b, treatment: LME: $\chi^{2}=13.0, d f=1, P=0.0003$ ) and the numbers of thrips increased through time (LME: $\left.\chi^{2}=112.1, d f=6, P<0.0001\right)$. There was no significant interaction between treatment and time (LME: $\chi^{2}=5.65$, $d f=6, P<0.46)$. More feeding scars were observed on clean plants than on treated plants during the experiments (Zhang personal observation).

Comparison of the two experiments (Fig. 3a and b) showed that the numbers of thrips on the control plants after $24 \mathrm{~h}$ did not differ significantly (GLM: $F_{1,28}=0.02$, 


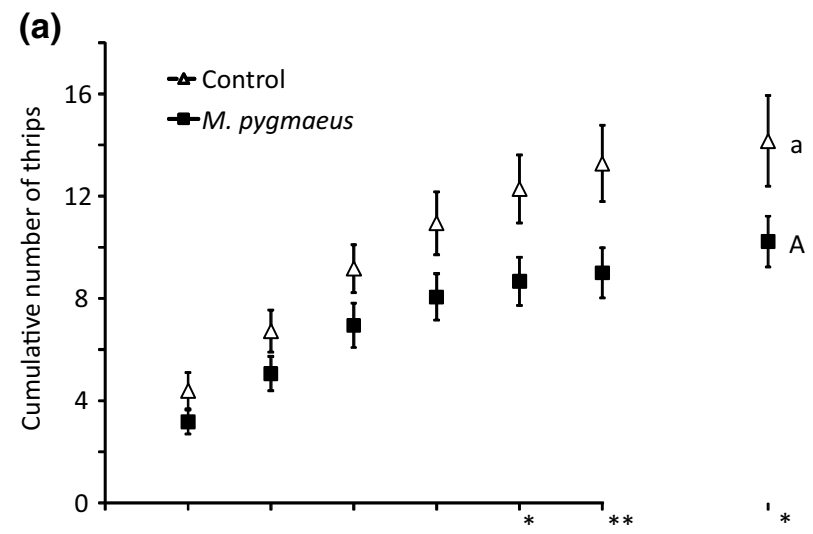

(b)

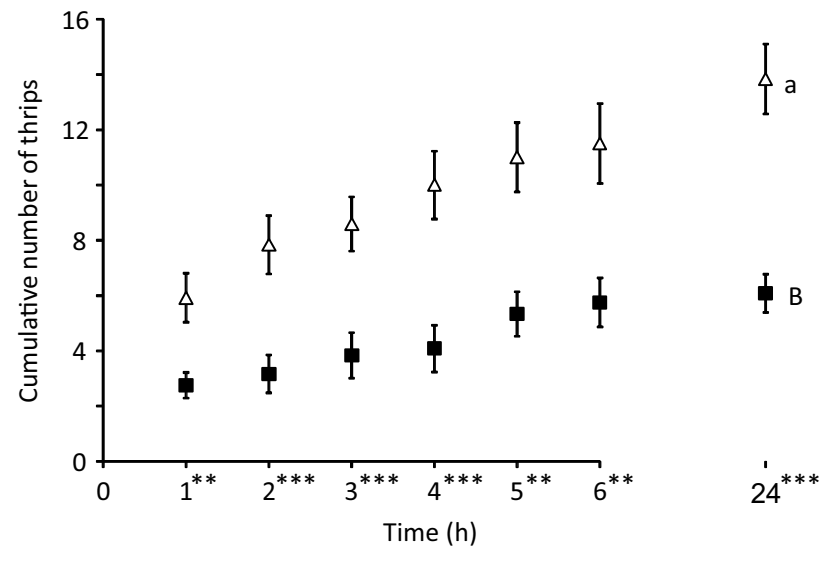

(c)

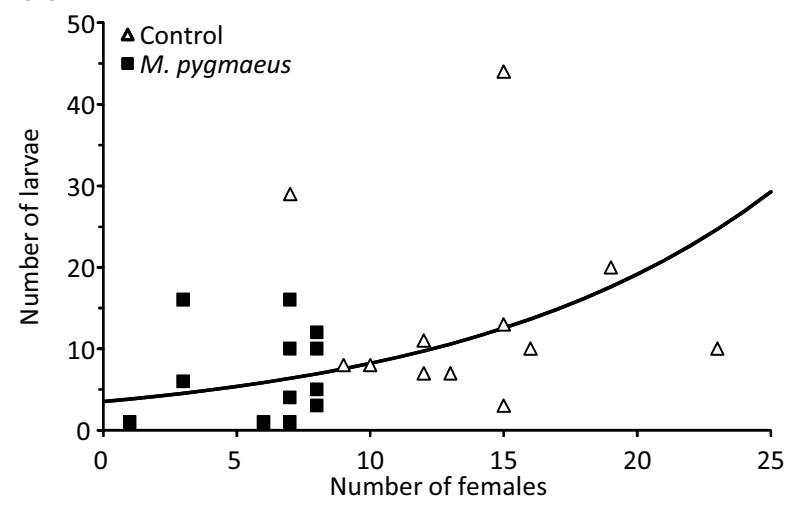

Fig. 3 Effect of previous exposure of plants to M. pygmaeus on the host plant choice and oviposition of thrips $F$. occidentalis. Average cumulative numbers of thrips $( \pm \mathrm{SE})$ on $M$. pygmaeus-exposed plants (closed squares) and clean plants (control, open triangles) over time, a when being released and recaptured within $1 \mathrm{~h}$ after landing on a plant and $\mathbf{b}$ when recaptured one day after being released. Significant differences between $M$. pygmaeus-treated and clean plants at each time point are indicated by asterisks (contrasts after LME, $* P<0.05, * * P<0.01, * * * P<0.001)$. Different letters at $24 \mathrm{~h}$ indicate significant differences between clean plants (small letters) and $M$. pygmaeus-treated plants (capital letters) of the two experiments (i.e. comparing Figs a and b, contrasts after LME: $P<0.05$ ). c Relation of the numbers of $F$. occidentalis larvae on the plants in the experiment with recapture after $24 \mathrm{~h}$ (b) and the numbers of females previously recaptured on these plants. Closed squares: M. pygmaeus-treated plants; open triangles: control, clean plants
$P=0.891)$. However, the numbers of thrips on the treated plants after $24 \mathrm{~h}$ were significantly lower in the experiment where thrips were not recaptured immediately (GLM: $\left.F_{1,28}=10.58, P=0.003\right)$. This suggests that thrips females moved away from the M. pygmaeus-exposed plants in the second experiment, where they had more time to do so.

The numbers of thrips larvae on treated and clean plants did not differ significantly (Fig. 3c, GLMM: $\chi^{2}=0.79, d f=1$, $P=0.375)$, but there was a significant positive effect of the numbers of females that had been recaptured on the plants on the numbers of larvae (Fig. 3c, GLMM: $\chi^{2}=38.9, d f=1$, $P<0.0001)$. This suggests that, once the females had chosen for a plant, they oviposited regardless of the plant treatment.

\section{Discussion}

We show that two species of herbivores preferred clean plants over plants previously exposed to the omnivorous predator M. pygmaeus. Higher numbers of spider mites chose clean plants rather than omnivore-treated plants. A clear trend of spider mites leaving the plants previously exposed to M. pygmaeus was shown 3-4 h after release. This suggests that spider mites changed host plant after assessing cues on the plant. The numbers of aphids on clean plants and plants previously exposed to M. pygmaeus was similar over time and showed even a slight tendency of preference for exposed plants (Fig. 2a). However, the proportions of aphids that left the omnivore-treated plants were significantly higher than the proportions that left the clean plants after $45 \mathrm{~min}$ and $24 \mathrm{~h}$, but this did not result in differences in the total numbers on the plants. Adult female thrips preferred clean plants over plants previously exposed to M. pygmaeus. When offered a chance to change host plants, the numbers of female thrips on omnivore-treated plants were significantly lower than when not offered such a chance (Fig. 3a, b). This suggests that, given more time to assess cues on the plants, thrips more strongly avoided plants exposed to M. pygmaeus. Overall, we conclude that spider mites and thrips preferred clean plants over plants previously exposed to M. pygmaeus, whereas aphids did not show a clear preference.

Earlier, we found that $M$. pygmaeus induced direct plant defences that lowered the reproduction rates of spider mites and thrips, but not of aphids (Zhang et al. 2018; see also Pappas et al. 2015). In particular, the reproduction rates of spider mites and thrips were lower on plants previously exposed to $M$. pygmaeus, and the juvenile development of thrips larvae was slower on plants previously exposed to M. pygmaeus (Zhang et al. 2018). In contrast, we found no significant effects of plant exposure on aphid performance. The plant preferences of spider mites and thrips observed here are in close agreement with these differences in performance, but can also be explained by these herbivores avoiding plants 
with cues of their predator, thus reducing predation risk. The lack of preference of aphids is also in agreement with their performance on clean plants and omnivore-exposed plants, but not with the aphids choosing plants with a lower predation risk. Macrolophus pygmaeus is a known efficient predator of aphids (Alvarado et al. 1997; Messelink et al. 2011), and it was therefore expected that aphids would avoid plants with this omnivore. Perhaps the aphids departed more from omnivore-exposed plants (Fig. 2b) in response to nonvolatile cues associated with the previous presence of the omnivore. Alternatively, it is possible that the aphids redistributed themselves over the two plants in an ideal-free manner (Fretwell and Lucas 1969).

It is known that aphids use both visual and olfactory cues to choose a suitable host plant from a distance (Powell et al. 2006). Previous reports have shown that M. persicae alighted equally on host and non-host plants, but left earlier from the non-host plant (Kennedy et al. 1959), in agreement with the behaviour of the apterous aphids tested here. However, it has been reported that alate and apterous morphs use different cues when choosing a host plant (Walling 2008); hence, the response of alate aphids to plants previously exposed to omnivores needs further study.

All herbivores were released some distance from the plants, and they could therefore perceive volatile cues associated with the suitability of a plant before contacting it. Moreover, aphids and thrips could also perceive visual cues. Although we did not perceive any signs of damage on $M$. pygmaeus-exposed plants, we cannot rule out the possibility that the herbivores perceived visual cues associated with plant feeding by the omnivore. Furthermore, it is known that spider mites, thrips and aphids use olfactory cues to locate host plants (Chapman et al. 1981; Dicke 1986; Nottingham et al. 1991; Gotoh et al. 1993; Pallini et al. 1997; de Kogel et al. 1999), and several herbivore species are known to avoid plants with heterospecific competitors (Byers and Wood 1980; Birch et al. 1980; Byers et al. 1984; Byers 1993; Pallini et al. 1997). Plants produce volatiles upon attacks by herbivores (Turlings et al. 1990; Dicke et al. 1990), and these volatiles vary quantitatively and qualitatively with herbivore species feeding on the plants (De Moraes et al. 1998; Birkett et al. 2003). Possibly, plants on which M. pygmaeus had fed also produce different volatiles from clean plants, and the herbivores tested here may have responded to these volatiles. Indeed, plant feeding by M. pygmaeus induced the production of new volatiles in bean plants (Moayeri et al. 2007), and plant feeding by the omnivorous Orius laevigatus induced volatile production in sweet pepper plants (Bouagga et al. 2018). It is possible that M. pygmaeus also induced the production of volatiles in sweet pepper plants in our study, which may have affected host plant choice of the herbivores. This is the subject of a further study.
Upon arrival on the plants previously exposed to $M$. pygmaeus, herbivores may have perceived that direct plant defences had been induced by M. pygmaeus (Zhang et al. 2018), whereupon they decided to search for a better host plant. This would explain the higher dispersal from exposed plants than from clean plants. It is known that herbivores avoid plants with cues associated with predation (Pallini et al. 1999a, b; Grostal and Dicke 1999; Choh and Takabayashi 2007); hence, the herbivores tested here may also have perceived cues such as faeces and other chemical markings left on the plants by M. pygmaeus (Moayeri et al. 2007), and this may have caused them to leave the plant. Although the herbivores tested here did not have contact with M. pygmaeus and the omnivores had mainly fed on plants and not on prey, it is possible that the herbivores had an innate aversion to cues associated with the omnivores (Pallini et al. 1999a, b; Grostal and Dicke 1999; Choh and Takabayashi 2007). Possibly, herbivores with previous experience with the omnivores and the associated predation risk would show stronger preferences than found here, as was described for whiteflies (Nomikou et al. 2003; Meng et al. 2006).

Macrolophus pygmaeus is commercially used for biological control of several pests in various crops in greenhouses (Messelink et al. 2015). Although it can also feed on plant tissue (Perdikis and Lykouressis 2000), plant damage is reported only when densities of the omnivores are very high (Castañé et al. 2011). In practice, these mirid bugs are released in the crop before pest invasions and are then mainly found in the flowers, where they feed on pollen and nectar (Messelink and Janssen 2014), but they may also feed on plant tissue. The young plants in this study were not flowering, thus forcing the omnivores to feed on leaves and stems. It remains to be investigated whether $M$. pygmaeus also induces plant defences in flowering plants.

We previously showed that the exposure of plants to $M$. pygmaeus decreases the plant quality for spider mites and thrips, but not for aphids (Zhang et al. 2018). Several other authors have shown similar effects for the same and other herbivore, omnivore and host plant species (Pappas et al. 2015; Pérez-Hedo et al. 2015a, b; Bouagga et al. 2018). Hence, omnivores do not only reduce herbivore damage directly by preying on them, but also indirectly by decreasing their performance through changes in plant quality. Furthermore, the exposure of plants to omnivores also affects herbivore host plant choice (this study; Pérez-Hedo et al. 2015a, b; Bouagga et al. 2018). It thus seems that the indirect, plant-mediated effects of omnivores on herbivores depend on the species of herbivore and omnivore and perhaps also on plant species. These effects need to be taken into account in studies of interactions in communities of plant-inhabiting arthropods as well as in studies on biological control. 


\section{Author Contribution Statement}

NXZ, GJM and AJ conceived and designed the experiments. NXZ and DvW performed experiments. NXZ and $\mathrm{AJ}$ analysed the data. NXZ and AJ wrote the manuscript. All authors commented and corrected it.

Acknowledgements We thank Enza Zaden Beheer B.V. for the supply of sweet pepper seeds, Koppert Biological Systems for the supply of Macrolophus and Ephestia eggs, Ludek Tikovsky for the assistance with the greenhouse experiments, Peter de Ruiter, Louise Vet, Michel Haring, Isabel Smallegange and Josep Jaques for comments on the manuscript and the population biology group for discussions. NXZ received a scholarship from the China Scholarship Council (CSC).

\section{Compliance with ethical standards}

Conflict of interest The authors declare no conflict of interest.

Human and animal rights All applicable international, national and/or institutional guidelines for the care and use of animals were followed. This article does not contain any studies with human participants performed by any of the authors.

Open Access This article is distributed under the terms of the Creative Commons Attribution 4.0 International License (http://creativeco mmons.org/licenses/by/4.0/), which permits unrestricted use, distribution, and reproduction in any medium, provided you give appropriate credit to the original author(s) and the source, provide a link to the Creative Commons license, and indicate if changes were made.

\section{References}

Agut B, Gamir J, Jaques JA, Flors V (2005) Tetranychus urticae-triggered responses promote genotype-dependent conspecific repellence or attractiveness in citrus. New Phytol 207:790-804

Alvarado P, Baltà O, Alomar O (1997) Efficiency of four Heteroptera as predators of Aphis gossypii and Macrosiphum euphorbiae (Hom.: Aphididae). Entomophaga 42:215-226

Atsatt PR (1981) Ant-dependent food plant selection by the mistletoe butterfly Ogyris amaryllis (Lycaenidae). Oecologia 48:60-63

Bates D, Mächler M, Bolker B, Walker S (2015) Fitting linear mixedeffects models using lme4. J Stat Softw 67:1-48

Bernays EA, Chapman RE (1994) Host-plant selection by phytophagous insects. Springer, Boston

Birch MC, Svihra P, Paine TD, Miller JC (1980) Influence of chemically mediated behavior on host tree colonization by four cohabiting species of bark beetles. J Chem Ecol 6:395-414

Birkett MA, Chamberlain K, Guerrieri E et al (2003) Volatiles from whitefly-infested plants elicit a host-locating response in the parasitoid, Encarsia formosa. J Chem Ecol 29:1589-1600

Bolter CJ, Dicke M, Loon JJAV et al (1997) Attraction of Colorado potato beetle to herbivore-damaged plants during herbivory and after its termination. J Chem Ecol 23:1003-1023

Bouagga S, Urbaneja A, Rambla JL et al (2018) Orius laevigatus strengthens its role as a biological control agent by inducing plant defenses. J Pest Sci 91:55-64
Byers JA (1993) Avoidance of competition by spruce bark beetles, Ips typographus and Pityogenes chalcographus. Experientia 49:272-275

Byers JA, Wood DL (1980) Interspecific inhibition of the response of the bark beetles, Dendroctonus brevicomis and Ips paraconfusus, to their pheromones in the field. J Chem Ecol 6:149-164

Byers JA, Wood DL, Craig J, Hendry LB (1984) Attractive and inhibitory pheromones produced in the bark beetle, Dendroctonus brevicomis, during host colonization: Regulation of inter- and intraspecific competition. J Chem Ecol 10:861-877

Castañé C, Arnó J, Gabarra R, Alomar O (2011) Plant damage to vegetable crops by zoophytophagous mirid predators. Biol Control 59:22-29

Chapman RF, Bernays EA, Simpson SJ (1981) Attraction and repulsion of the aphid, Cavariella aegopodii, by plant odors. J Chem Ecol 7:881-888

Choh Y, Takabayashi J (2007) Predator avoidance in phytophagous mites: response to present danger depends on alternative host quality. Oecologia 151:262-267

Crawley MJ (2013) The R Book. Wiley, Chicester

Darshanee HLC, Ren H, Ahmed N et al (2017) Volatile-mediated attraction of greenhouse whitefly Trialeurodes vaporariorum to tomato and eggplant. Front Plant Sci 8:1285

de Kogel WJ, Koschier EH, Visser JH (1999) Y-tube olfactometer to determine the attractiveness of plant volatiles to western flower thrips. Exp Appl Entomol 10:131-136

De Moraes CM, Lewis WJ, Paré PW et al (1998) Herbivore-infested plants selectively attract parasitoids. Nature 393:570-573

De Moraes CM, Mescher MC, Tumlinson JH (2001) Caterpillarinduced nocturnal plant volatiles repel conspecific females. Nature 410:577-580

Dias CR, Bernardo AMG, Mencalha J et al (2016) Antipredator behaviours of a spider mite in response to cues of dangerous and harmless predators. Exp Appl Acarol 69:263-276

Dicke M (1986) Volatile spider-mite pheromone and host-plant kairomone, involved in spaced-out gregariousness in the spider mite Tetranychus urticae. Physiol Entomol 11:251-262

Dicke M (2000) Chemical ecology of host-plant selection by herbivorous arthropods: a multitrophic perspective. Biochem Syst Ecol 28:601-617

Dicke M, Sabelis MW (1988) How plants obtain predatory mites as bodyguards. Neth J Zool 38:148-165

Dicke M, Beek TAV, Posthumus MA et al (1990) Isolation and identification of volatile kairomone that affects acarine predatorprey interactions. Involvement of host plant in its production. $\mathbf{J}$ Chem Ecol 16:381-396

Dicke M, van Loon JJA, Soler R (2009) Chemical complexity of volatiles from plants induced by multiple attack. Nat Chem Biol $5: 317-324$

Fretwell SD, Lucas HL (1969) On territorial behavior and other factors influencing habitat selection in birds. Acta Biotheoret 19:16-36

Gerling D (1990) Whiteflies: their bionomics, pest status and management. Intercept Limited, Andover

Gotoh T, Bruin J, Sabelis MW, Menken SBJ (1993) Host race formation in Tetranychus urticae: genetic differentiation, host plant preference, and mate choice in a tomato and a cucumber strain. Entomol Exp Appl 68:171-178

Grostal P, Dicke M (1999) Direct and indirect cues of predation risk influence behavior and reproduction of prey: a case for acarine interactions. Behav Ecol 10:422-427

Harari AR, Ben-Yakir D, Rosen D (1994) Mechanism of aggregation behavior in Maladera matrida Argaman (Coleoptera: Scarabaeidae). J Chem Ecol 20:361-371 
Harrewijn P, Piron PGM, Mollema C (1996) Electrically recorded probing behaviour of thrips species on optimal and suboptimal hosts. Entomol Exp Appl 80:43-45

Janssen A (1999) Plants with spider-mite prey attract more predatory mites than clean plants under greenhouse conditions. Entomol Exp Appl 90:191-198

Janssen A, Pallini A, Venzon M, Sabelis MW (1998) Behaviour and indirect interactions in food webs of plant-inhabiting arthropods. Exp Appl Acarol 22:497-521

Karban R, Baldwin IT (1997) Induced responses to herbivory. University of Chicago Press, Chicago

Kennedy JS, Booth CO, Kershaw WJS (1959) Host finding by aphids in the field: gynoparae of Myzus persicae (Sulzer). Ann Appl Biol 47:410-423

Lee D-H, Nyrop JP, Sanderson JP (2011) Avoidance of natural enemies by adult whiteflies, Bemisia argentifolii, and effects on host plant choice. Biol Control 58:302-309

Lenth RV (2016) Least-squares means: the R package lsmeans. J Stat Softw 69:1-33

Lima SL, Dill LM (1990) Behavioral decisions made under the risk of predation: a review and prospectus. Can J Zool 68:619-640

Loughrin JH, Potter DA, Hamilton-Kemp TR (1995) Volatile compounds induced by herbivory act as aggregation kairomones for the Japanese beetle (Popillia japonica Newman). J Chem Ecol $21: 1457-1467$

Meng R-X, Janssen A, Nomikou M et al (2006) Previous and present diets of mite predators affect antipredator behaviour of whitefly prey. Exp Appl Acarol 38:113-124

Messelink GJ, Janssen A (2014) Increased control of thrips and aphids in greenhouses with two species of generalist predatory bugs involved in intraguild predation. Biol Control 79:1-7

Messelink GJ, Bloemhard CM, Kok L, Janssen A (2011) Generalist predatory bugs control aphids in sweet pepper. IOBC/wprs Bull 68:115-118

Messelink GJ, Bloemhard CMJ, Hoogerbrugge H et al (2015) Evaluation of mirid predatory bugs and release strategy for aphid control in sweet pepper. J Appl Entomol 139:333-341

Moayeri HRS, Ashouri A, Brødsgaard HF, Enkegaard A (2007) Males of the predatory mirid bug Macrolophus caliginosus exploit plant volatiles induced by conspecifics as a sexual synomone. Entomol Exp Appl 123:49-55

Müller CB, Godfray HCJ (1999) Predators and mutualists influence the exclusion of aphid species from natural communities. Oecologia 119:120-125

Müller C, Riederer M (2005) Plant surface properties in chemical ecology. J Chem Ecol 31:2621-2651

Neal JW, Bentz J-A (1999) Evidence for the stage inducing phenotypic plasticity in pupae of the polyphagous whiteflies Trialeurodes vaporariorum and Bemisia argentifolii (Homoptera: Aleyrodidae) and the raison d'être. Ann Entomol Soc Am 92:774-787

Nomikou M, Janssen A, Sabelis MW (2003) Herbivore host plant selection: whitefly learns to avoid host plants that harbour predators of her offspring. Oecologia 136:484-488

Nottingham SF, Hardie J, Dawson GW et al (1991) Behavioral and electrophysiological responses of aphids to host and nonhost plant volatiles. J Chem Ecol 17:1231-1242

Pallini A, Janssen A, Sabelis MW (1997) Odour-mediated responses of phytophagous mites to conspecific and heterospecific competitors. Oecologia 110:179-185

Pallini A, Janssen A, Sabelis MW (1999a) Spider mites avoid plants with predators. Exp Appl Acarol 23:803-815

Pallini A, Janssen A, Sabelis MW (1999b) Do western flower thrips avoid plants infested with spider mites? Interactions between potential competitors. In: Bruin J, van der Geest LPS, Sabelis MW (eds) Ecology and evolution of the Acari. Springer, Berlin, pp 375-380
Pappas ML, Steppuhn A, Geuss D et al (2015) Beyond predation: the zoophytophagous predator Macrolophus pygmaeus induces tomato resistance against spider mites. PLoS ONE 10:e0127251

Perdikis DC, Lykouressis DP (2000) Effects of various items, host plants, and temperatures on the development and survival of Macrolophus pygmaeus Rambur (Hemiptera: Miridae). Biol Control 17:55-60

Perdikis DC, Lykouressis DP (2004) Myzus persicae (Homoptera: Aphididae) as suitable prey for Macrolophus pygmaeus (Hemiptera: Miridae) population increase on pepper plants. Environ Entomol 33:499-505

Pérez-Hedo M, Bouagga S, Jaques JA et al (2015a) Tomato plant responses to feeding behavior of three zoophytophagous predators (Hemiptera: Miridae). Biol Control 86:46-51

Pérez-Hedo M, Urbaneja-Bernat P, Jaques JA et al (2015b) Defensive plant responses induced by Nesidiocoris tenuis (Hemiptera: Miridae) on tomato plants. J Pest Sci 88:543-554

Pierce NE, Elgar MA (1985) The influence of ants on host plant selection by Jalmenus evagoras, a myrmecophilous lycaenid butterfly. Behav Ecol Sociobiol 16:209-222

Pierce NE, Young WR (1986) Lycaenid butterflies and ants: twospecies stable equilibria in mutualistic, commensal, and parasitic interactions. Am Nat 128:216-227

Powell G, Tosh CR, Hardie J (2006) Host plant selection by aphids: behavioral, evolutionary, and applied perspectives. Annu Rev Entomol 51:309-330

R Development Core Team (2014) R: A language and environment for statistical computing (Version 3.0. 2). R Found Stat Comput Vienna Austria

Sabelis MW, Takabayashi J, Janssen A et al (2007) Ecology meets plant physiology: herbivore-induced plant responses and their indirect effects on arthropod communities. In: Ohgushi T, Craig TP, Price PW (eds) Ecological communities: plant mediation in indirect interaction webs. Cambridge University Press, Cambridge, pp $188-217$

Sarmento RA, Lemos F, Bleeker PM et al (2011) A herbivore that manipulates plant defence. Ecol Lett 14:229-236

Schoonhoven LM (1990) Host-marking pheromones in Lepidoptera, with special reference to two Pieris spp. J Chem Ecol 16:3043-3052

Shiojiri K, Takabayashi J, Yano S, Takafuji A (2002) Oviposition preferences of herbivores are affected by tritrophic interaction webs. Ecol Lett 5:186-192

Takabayashi J, Sabelis MW, Janssen A et al (2006) Can plants betray the presence of multiple herbivore species to predators and parasitoids? The role of learning in phytochemical information networks. Ecol Res 21:3-8

Turlings TCJ, Tumlinson JH, Lewis WJ (1990) Exploitation of herbivore-induced plant odors by host-seeking parasitic wasps. Science 250:1251-1253

van Houten YM, Glas JJ, Hoogerbrugge H et al (2013) Herbivory-associated degradation of tomato trichomes and its impact on biological control of Aculops lycopersici. Exp Appl Acarol 60:127-138

Visser JH (1986) Host odor perception in phytophagous insects. Annu Rev Entomol 31:121-144

Wagner D, Kurina L (1997) The influence of ants and water availability on oviposition behaviour and survivorship of a facultatively anttended herbivore. Ecol Entomol 22:352-360

Walling LL (2008) Avoiding effective defenses: strategies employed by phloem-feeding insects. Plant Physiol 146:859-866

Zarate SI, Kempema LA, Walling LL (2007) Silverleaf whitefly induces salicylic acid defenses and suppresses effectual jasmonic acid defenses. Plant Physiol 143:866-875

Zhang NX, Messelink GJ, Alba JM et al (2018) Phytophagy of omnivorous predator Macrolophus pygmaeus affects performance of herbivores through induced plant defences. Oecologia 186:101-113 